\title{
PERANCANGAN MEDIA VIDEO PROFILE BERBENTUK PROMOSI DAN INFORMASI DI SMK YUPPENTEK 4 CILEDUG TANGERANG
}

\author{
Wahyu Hidayat ${ }^{1}$ \\ Suhendra ${ }^{2}$ \\ Ade Maulana $^{3}$ \\ Alumni Sarjana Broadcasting Universitas Esa Unggul Jakarta ${ }^{1}$, STMIK Raharja Jurusan Teknik \\ Informatika ${ }^{2,3}$ \\ Jl. Terusan Arjuna Tol Tomang, Kebon Jeruk, Jakarta ${ }^{1}$, Jl. Jendral Sudirman No. 40, Modernland, Tangerang ${ }^{2,3}$ \\ Email : wahyu.hidayat@ raharja.info ${ }^{I)}$ suhendra@ raharja.info ${ }^{21}$, ade.maulana@ raharja.info ${ }^{3)}$
}

\begin{abstract}
ABSTRAK
Perkembangan ilmu pengetahuan dan informasi membuat berbagai aktifitas dan kehidupan seharihari tidak lepas dari informasi yang didapat baik dari media cetak maupun media elektronik. Peranan teknologi informasi dan multimedia juga tidak ketinggalan, berbagai informasi ditawarkan dengan bentuk multimedia yang dapat menciptakan presentasi interaktif dan informatif dengan mengkombinasikan teks, audio, video, animasi dan grafik yang digunakan untuk keunggulan bersaing Perkembangan dunia pendidikan yang makin pesat, menyebabkan semakin banyaknya fasilitas dan keunggulan yang harus di promosikan untuk bersaing khususnya pada SMK Yuppentek 4 Ciledug Tangerang. Tujuan dari penelitian ini adalah merancang media berbasis audio visual agar dapat menjadi daya tarik yang efektif, terutama dalam penyampaian informasi dan promosi mengenai hal hal yang berkaitan dengan keseluruhan SMK Yuppentek 4 Ciledug Tangerang. SMK Yuppentek 4 Ciledug Tangerang merupakan sekolah yang terletak di Tangerang. Permasalahan yang ada yaitu media yang digunakan oleh SMK SMK Yuppentek 4 Ciledug Tangerang masih berupa media Cetak, pada umumnya masyarakat lebih mudah menerima informasi melalui media yang interaktif dan komunikatif, sehingga SMK Yuppentek 4 Ciledug Tangerang membutuhkan media video profile sebagai media penunjang informasi dan promosi yang di tunjukkan kepada calon siswa dan siswi SMK Yuppentek 4 Ciledug Tangerang, ataupun sebagai media informasi kepada masyarakat, sehingga perancangan media video profile yang menampilkan seluruh ruang lingkup, keunggulan, dan fasilitas yang dimiliki SMK Yuppentek 4 Ciledug Tangerang tersebut, dapat menjadi solusi dalam pemecahan masalah pada media promosi dan informasinya. Dengan ini penulis membuat penelitian dengan judul "PERANCANGAN MEDIA VIDEO PROFILE BERBENTUK PROMOSI DAN INFORMASI DI SMK YUPPENTEK 4 CILEDUG TANGERANG”.
\end{abstract}

Kata kunci : Promosi, Audio Visual, Video Profile.

\begin{abstract}
Development of science and information makes a variety of activities and life sehari-hari of the information gained from the media, both print and electronic media. The role of information technology and multimedia are also not to miss, a variety of information offered by the form of multimedia that can create interactive and informative presentation by combining text, audio, video, animation and graphics used for competitive advantage Development education grew rapidly, causing a growing number of facilities and advantages that should be promoted to compete, especially at SMK Yuppentek 4 Ciledug Tangerang. The purpose of this research is to design-based audio visual media in order to be an effective appeal, especially in the delivery of information and promotions regarding things - things that are related to the overall CMS Yuppentek 4 Ciledug Tangerang. SMK Yuppentek 4 Ciledug Tangerang is located in Tangerang. Existing problems, namely the medium used by the SMK SMK Yuppentek 4 Ciledug Tangerang was a print media, in general the community more receptive of
\end{abstract}


information via media interactive and communicative, so CMS Yuppentek 4 Ciledug Tangerang requires video media profile as a media of supporting information and promotion on the show to prospective students and students of SMK Yuppentek 4 Ciledug Tangerang, or as a media information to the public, so the design of video media profile that displays the entire scope, advantages and facilities belonging to SMK Yuppentek 4 Ciledug Tangerang, can be a solution in solving problems in media promotion and information. With this author makes research with the title "THE DESIGN OF VIDEO MEDIA PROFILE INFORMATION ON PROMOTIONS AND SHAPED SMK YUPPENTEK 4 CILEDUG TANGERANG".

Keywords : Promotion, Audio Visual, Video Profile.

\section{PENDAHULUAN}

Perkembangan ilmu pengetahuan dan informasi membuat berbagai aktifitas dan kehidupan sehari-hari tidak lepas dari informasi yang didapat baik dari media cetak maupun media elektronik. Peranan teknologi informasi dan multimedia juga tidak ketinggalan, berbagai informasi ditawarkan dengan bentuk multimedia yang dapat menciptakan presentasi interaktif dan informatif dengan mengkombinasikan teks, audio, video, animasi dan grafik yang digunakan untuk keunggulan bersaing.

Pengenalan dunia pendidikan dengan teknologi informasi multimedia saat ini sangat diperlukan, karena sebagai sarana informasi untuk para calon siswa dan siswi, orang tua siswa dan siswi atau bahkan masyarakat yang mempunyai kepentingan dengan pihak sekolah. Informasi ini sangat dibutuhkan oleh para calon siswa yang akan masuk kesekolah barunya, sehingga calon siswa dapat mengetahui berbagai fasilitas yang ada pada sekolah barunya, seperti laboratorium yang memadai, perpustakaan dan ruang kelas yang nyaman, serta berbagai kegiatan ekstrakulikuler yang ada. Informasi yang didapat akan menjadi tolak ukur bagi siswa untuk masuk sekolah yang diinginkan, serta bagi orang tua dapat memotivasi anakanaknya untuk memilih sekolah yang mempunyai keunggulan dan kelebihan yang menjadikan sekolah andalan, unggulan maupun sekolah favorit.

Berawal dari berdirinya Yayasan Usaha Peningkatan Pendidikan Teknologi (YUPPENTEK) yang berada di Kota
Tangerang, yang didirikan Oleh Bapak. H. MA. Thahirudin. Pada tahun 1992. Melihat potensi untuk meningkatkan dunia pendidikan di ciledug yang sangat besar, pengurus cabang YUPPENTEK yang berada di ciledug berinisiatif lebih meningkatkan kualitas pendidikan di daerah dan melakukan pembaharuan dan pembuatan system yang lebih baik. Maka berdirilah Yayasan Terpadu AT Thahirin Ciledug, yang di dirikan oleh Bapak. H. MA. Thahirudin di mana beliau juga adalah salah satu pendiri YUPPENTEK Tangerang. STM YUPPENTEK 4 Ciledug yang kini menjadi SMK YUPPENTEK 4 Ciledug yang di pimpin oleh Bapak. Ir. H. MA. Rusli Thahir, MM adalah salah satu unit yang berada di bawah Yayasan Pendidikan Terpadu AT Thahirin yang beralamat di Jl. Raden Fatah Km.1 Ciledug Tangerang

\section{RUMUSAN MASALAH}

Masalah mengenai informasi tentang SMK Yuppentek 4 Ciledug Tangerang, dapat ditarik kesimpulan bahwa para calon siswa dan siswi belum mengetahui dengan jelas tentang profile SMK Yuppentek 4 Ciledug Tangerang, karena dengan menggunakan media cetak. Informasi dan cara penyampaiannya saat ini belum efektif.

Media video profile dinilai lebih efektif karena manusia dapat mengingat sebanyak $80 \%$ apa yang dilihat, didengar dan dialaminya secara bersamaan dan karna video dapat menarik perhatian 
masyarakat serta calon siswa dan siswi SMK Yuppentek 4 Ciledug Tangerang.

\section{LANDASAN TEORI}

\section{Landasan Teori}

- Pengertian Perancangan

Perancangan adalah wujud visual yang dihasilkan dari bentuk-bentuk kreatif yang telah direncanakan. Langkah awal dalam perancangan desain bermula dari hal-hal yang tidak teratur berupa gagasan atau ide-ide kemudian melalui proses penggarapan dan pengelolaan akan menghasilkan hal-hal yang teratur, sehingga hal-hal yang sudah teratur bisa memenuhi fungsi dan kegunaan secara baik $^{[5]}$.

\section{- Konsep Dasar Video Profile}

profile perusahaan (corporate profile) merupakan video yang diproduksi untuk keperluan tertentu, misalnya memperkenalkan suatu perusahaan tertentu untuk disebarluaskan ke publik, selain itu sering dipakai sebagai sarana pendukung dalam suatu presentasi perusahaan atau kelompok tertentu.

\section{- Konsep Dasar Promosi dan Informasi}

Pengertian promosi merupakan salah satu faktor penentu keberhasilan suatu program pemasaran. Betapapun berkualitasnya suatu produk, bila konsumen belum pernah mendengarnya dan tidak yakin produk itu akan berguna bagi mereka, maka mereka tidak akan pernah membelinya. Pentingnya promosi dapat digambarkan lewat perumpamaan bahwa pemasaran tanpa promosi dapat diibaratkan seorang pria berkaca mata hitam yang dari tempat gelap pada malam kelam mengedipkan matanya pada seorang gadis cantik di kejauhan.

pada hakikatnya promosi adalah suatu bentuk komunikasi pemasaran. Yang dimaksud dengan komunikasi pemasaran adalah aktivitas pemasaran yang berusaha menyebarkan informasi, mempengaruhi atau membujuk dan mengingatkan pasar sasaran atas perusahaan dan produknya agar bersedia menerima, membeli dan setia pada produk yang ditawarkan perusahaan yang bersangkutan ${ }^{[4]}$.

\section{- Konsep Dasar Informasi}

Informasi adalah data yang telah diolah menjadi sebuah bentuk yang lebih berarti bagi penerimanya, dan bermanfaat dalam mengambil sebuah keputusan.

informasi (information) dapat didefinisikan sebagai berikut: "Informasi adalah data yang diolah menjadi bentuk yang lebih berguna dan lebih berarti bagi yang menerimannya, informasi disebut juga data yang diproses atau data yang memiliki arti ${ }^{[8]}$.

- Tahapan Produksi Audio Visual Pra Produksi

Pra produksi adalah tahapan sebelum diproduksi secara nyata ${ }^{[3]}$.

- Produksi

Produksi adalah tahapan pengambilan data yang dibutuhkan sesuai script dan storyboard. Disini crew dan actor banyak berkomunikasi dilapangan produksi.

- Pasca Produksi

Pasca Produksi adalah mengolah data data yang diambil di tahap produksi, sehingga bisa menjadi bahan jadi atau final yang siap untuk diedarkan.

- Multimedia Audio Visual Dan Broadcasting

Definisi Multimedia

Multimedia adalah penggunaan komputer untuk menampilkan teks, grafik, video, animasi dan suara dalam bentuk $\operatorname{terpadu}^{[2]}$.

- Definisi Audio Visual perkembangan teknologi dunia audio visual telah banyak mewarnai kehidupan manusia dari berbagai aspek kehidupan. 
- Definisi Broadcasting

Broadcasting adalah kegiatan dalam cara menyampaikan pesan, ide, hasrat, kepada khalayak dengan menggunakan fasilitas frequency, dengan kata lain dunia broadcasting adalah merupakan suatu kegiatan penyiaran yang dilakukan oleh seorang penyiar ${ }^{[1]}$.

- Pengertian Sinopsis

Sinopsis adalah ringkasan cerita media periklanan atau film, merupakan bentuk atau pendekatan dari sebuah periklanan atau film dengan tetap memperhatikan unsur-unsur pencerminan dari sebuah periklanan atau film tersebut ${ }^{[6]}$.

- Pengertian Storyboard

Story Board adalah rangkaian gambar ilustrasi yang berusaha menjelaskan bahasa tulisan scenario kedalam bahasa visual $^{[7]}$.

\section{- Preproduction}

Untuk Preproduction adalah step atau langkah dimana dimulainya ide, perencanaan dan persiapan dari Konsep Produksi MAVIB. Ada tujuh langkah Preproduction dalam Konsep Produksi MAVIB, dimulai dari Ide yang dituangkan secara sistematis, lalu diikuti dengan pembuatan sinopsis, Script Writting dan Storyboard.Dua tahapan terakhir adalah pemilihan pemain dan crew dan Setting Alat. Semua tahapan yang ada harus sesuai TimeSchedule yang ditetapkan. Untuk lebih jelasnya di ilustrasikan pada bagan berikut ini :

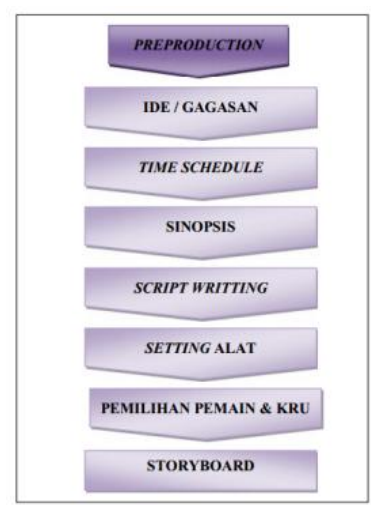

Gambar 1. Preproduction

\section{Time Schedule}

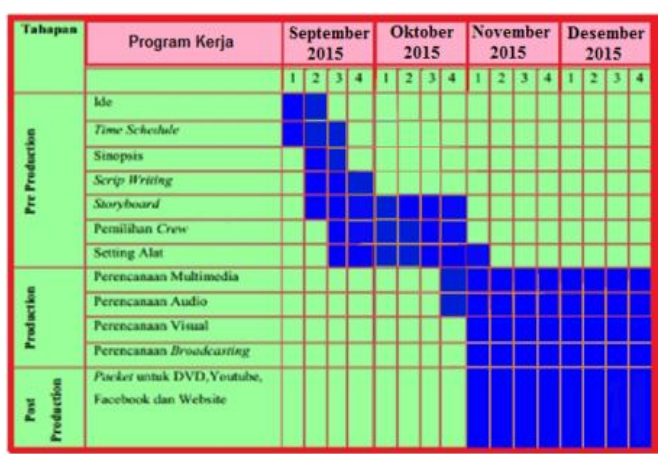

\section{Gambar 2. Time Schedule}

- Sinopsis

Adalah ringkasan cerita atau film, menjadi bentuk pemendekan dari sebuah feature documenter tersebut. Sinopsis biasanya dibatasi oleh jumlah halaman, misalnya satu atau dua halaman, seperlima atau sepersepuluh dari panjang feature documenter. Sinopsis perancangan video profile sebagai penunjang media informasi dan promosi pada SMK Yuppentek 4 Ciledug Tangerang ini adalah :

"STM YUPPENTEK 4 Ciledug yang kini menjadi SMK YUPPENTEK 4 Ciledug yang di pimpin oleh Bapak. Ir. H. MA. Rusli Thahir, MM adalah salah satu unit yang berada di bawah Yayasan Pendidikan Terpadu AT Thahirin yang beralamat di Jl. Raden Fatah km.1 Ciledug kota Tangerang. SMK dilengkapi dengan fasilitas ruang kelas yang nyaman, Ruang praktek masing masing kejuruan, laboratorium komputer, perpustakaan, dan Masjid sebagai tempat beribadah serta berbagai kegiatan ekstrakulikuler seperti Futsal, Rohis, Pramuka dan paskibra, Sekolah ini mempunyai komitmen yang tinggi untuk meningkatkan kualitas peserta didik dan dapat menciptakan Sumber Daya Manusia ( SDM ) yang berkualitas dan memiliki kompetensi di bidangnya". 


\section{Storyboard}

Scene 1

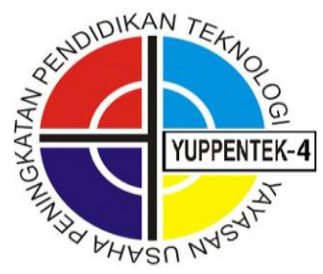

Gambar 3. Logo Sekolah

Bumper Opening SMK Yupentek 4

\section{Scene 2}

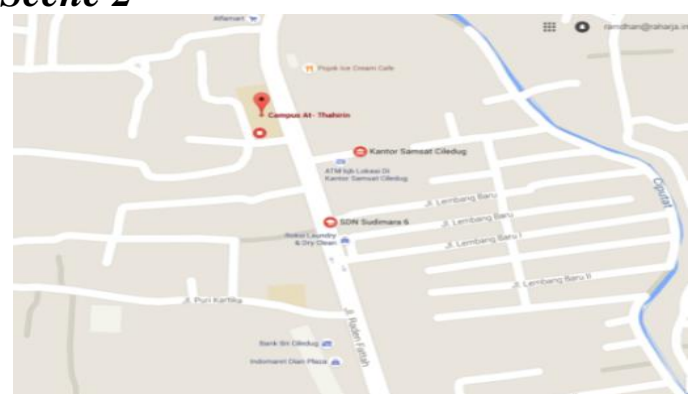

Gambar 4: Video Peta lokasi SMK yuppentek 4 Ciledug Tangerang

\section{Bird Eye / EXT \\ Menggambarkan peta lokasi menuju SMK Yunnentek 4}

\section{Scene 3}

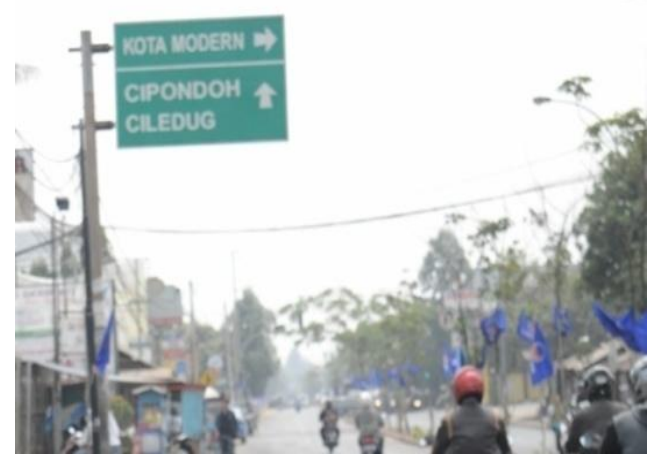

Gambar 5: Video Jalan menuju SMK Yuppentek 4 Ciledug Tangerang

Medium Long Shoot (MLS) / EXT

Menggambarkan peta lokasi menuju SMK Yuppentek 4

\section{Scene 4}

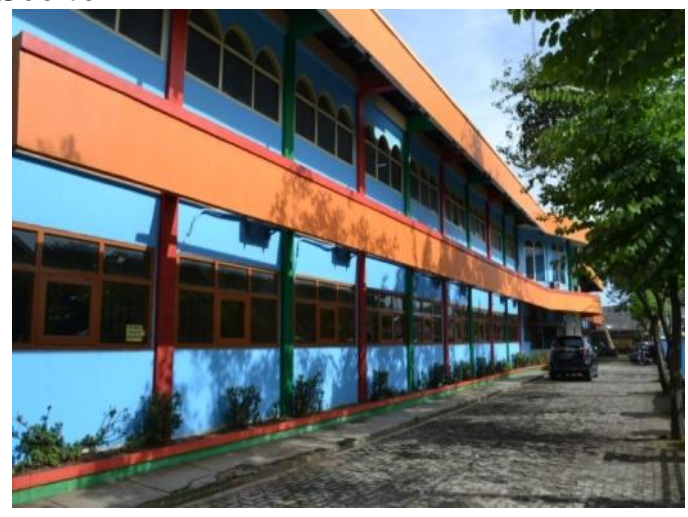

Gambar 6: Video keseluruhan gedung Sekolah

Full Shoot (FS) / EXT

Menggambarkan Lingkungan sekolah

\section{Scane 5}

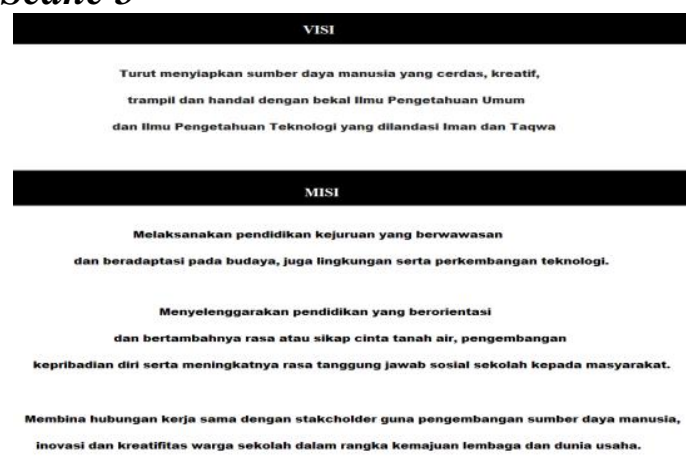

Gambar 7: Video Visi dan Misi

Visi Misi SMK Yuppentek 4

Scene 6

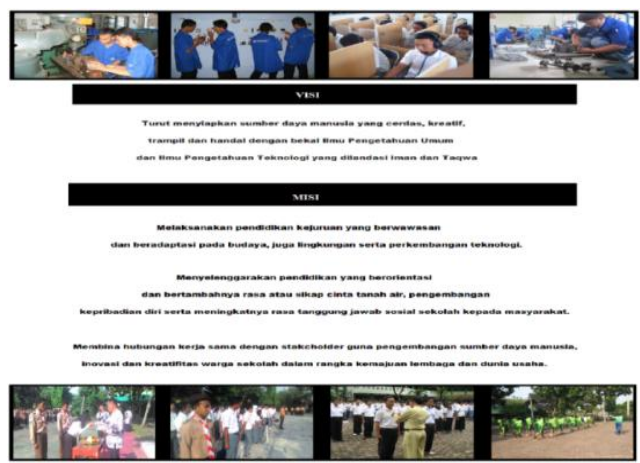

Gambar 8: Video Slide foto-foto kegiatan SMK Yuppentek 4 Ciledug Tangerang

Slide foto-foto kegiatan SMK Yuppentek 4 Ciledug Tangerang 


\section{Scene 7}

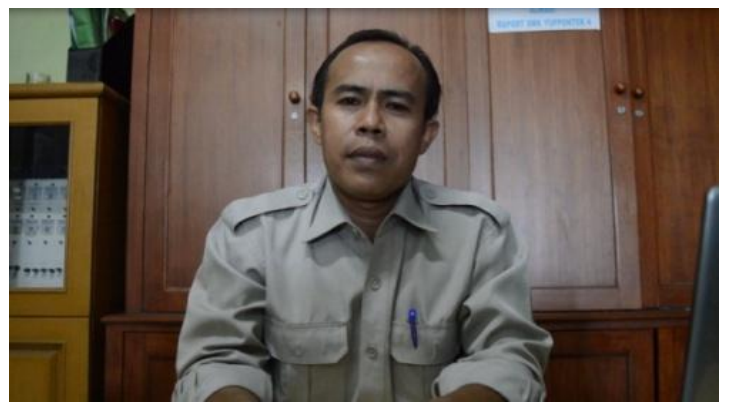

Gambar 8: Video Wawancara kepala sekolah

Medium close up (MCU) / INT

Menggambarkan Wawancara Kepala Sekolah SMK Yuppentek 4

\section{Scene 8}

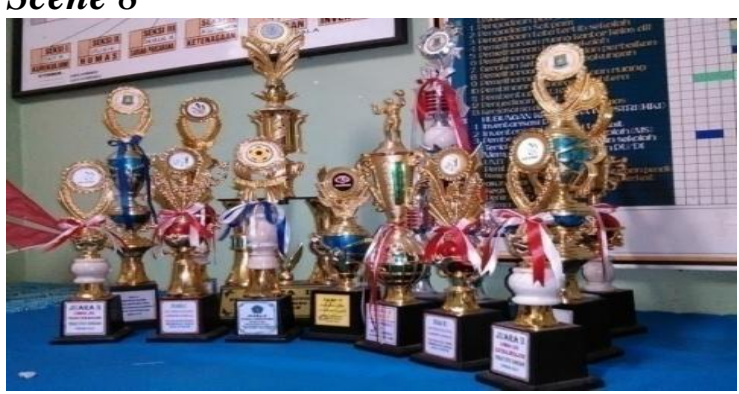

Gambar 9: Video Piagam prestasi SMK Yuppentek 4 Ciledug Tangerang

Full Shoot (FS) / INT

Menggambarkan Piagam prestasi SMK Yuppentek 4 Ciledug Tangerang

\section{Scene 9}

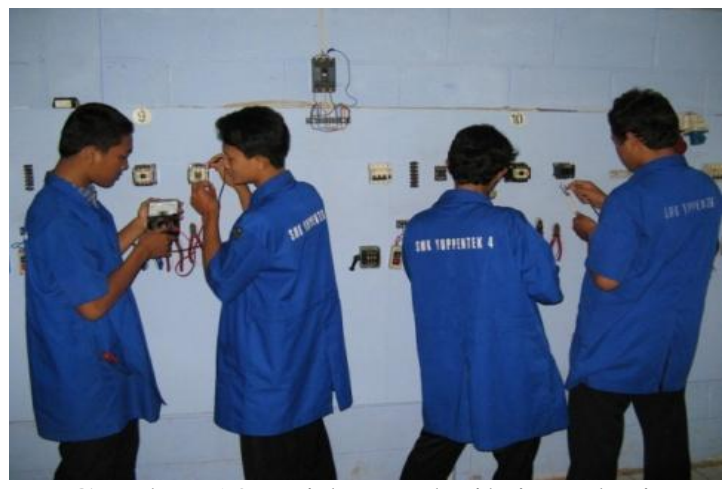

Gambar 10: Video Teknik instalasi tenaga listrik

\section{Long medium (LM)/ INT}

Menggambarkan Jurusan Teknik instalasi tenaga listrik
Scene 10

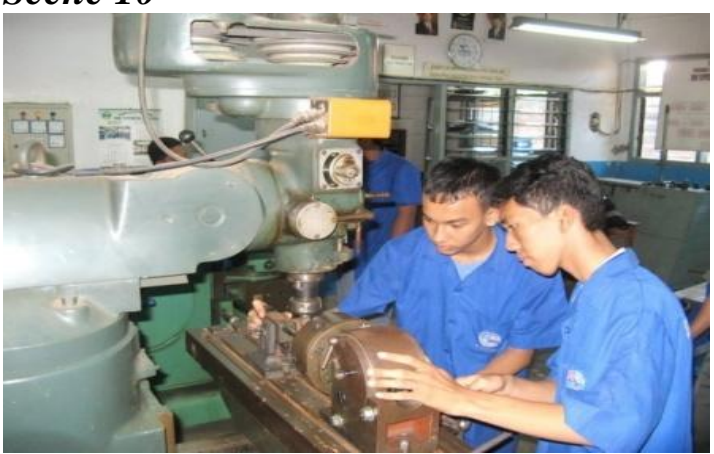

Gambar 11: Video Teknik pemesinan

Medium Shoot (MS) / INT

Menggambarkan Jurusan Teknik Permesinan

\section{Scene 11}

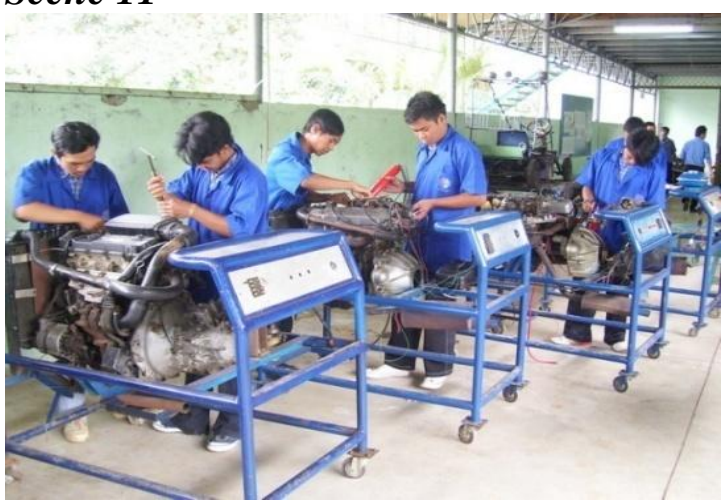

Gambar 12: Video teknik otomotif

Full Shoot (FS) / INT

Menggambarkan Jurusan Teknik Otomotif

Scene 12

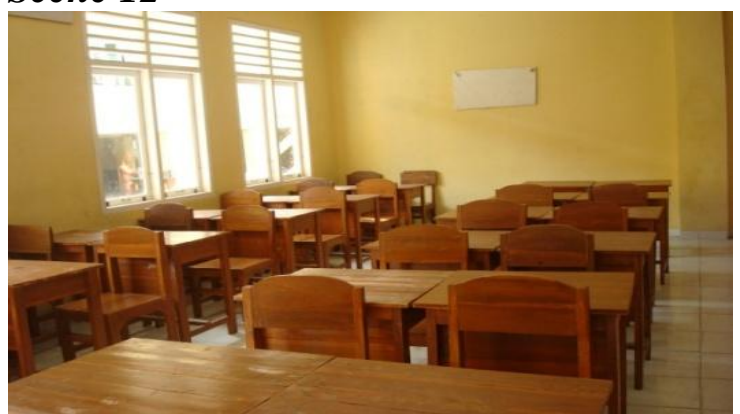

Gambar 13: Video Ruang kelas

Full shoot (FS) / INT

Menggambarkan Ruang Kelas SMK Yuppentek 4 


\section{Scene 13}

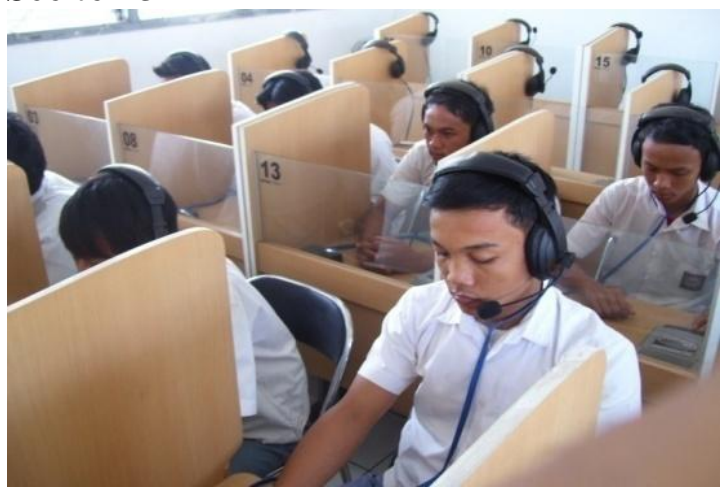

Gambar 14: Video Ruang laboratorium komputer

\section{Medium Shoot (MS) / INT \\ Menggambarkan Ruang Laboratorium Komputer SMK Yuppentek 4}

\section{Scene 14}

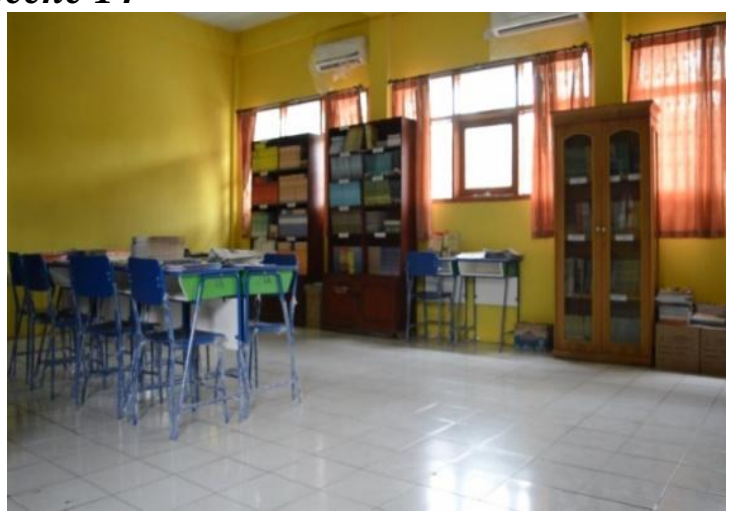

Gambar 15: Video Perpustakaan SMK Yuppentek 4 Ciledug Tangerang

Full Shoot (FS) / INT

Menggambarkan Ruang Perpustakaan SMK Yuppentek 4

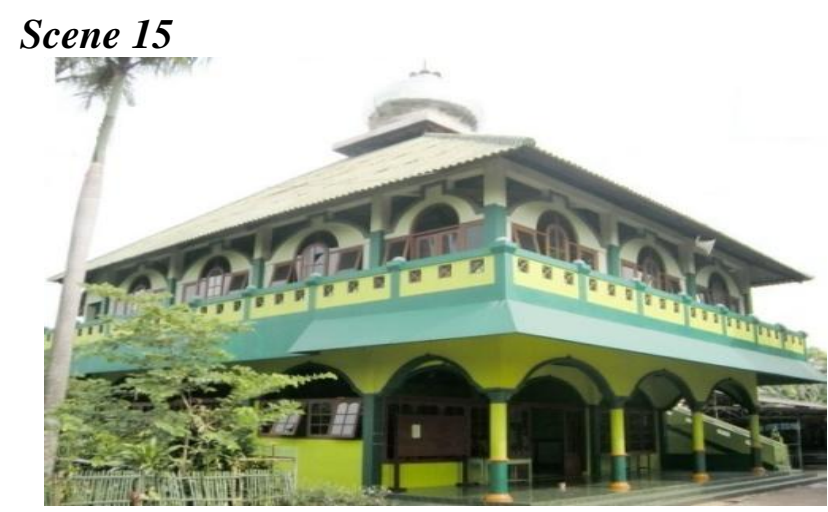

Gambar 16: Video Mesjid SMK

Yuppentek 4 Ciledug Tangerang

Full Shoot (FS) / EXT

Menggambarkan Masjid SMK

Yuppentek 4

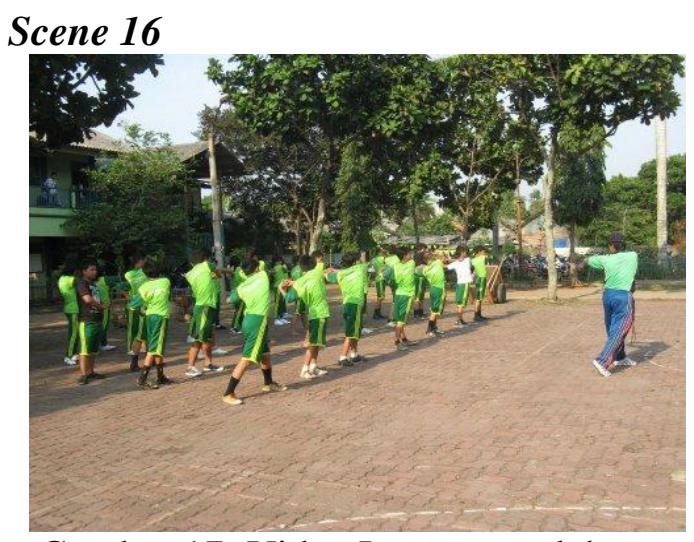

Gambar 17: Video Lapangan olahraga

Full Shoot (FS) / EXT

Menggambarkan Lapangan SMK Yuppentek 4

\section{Scene 17}

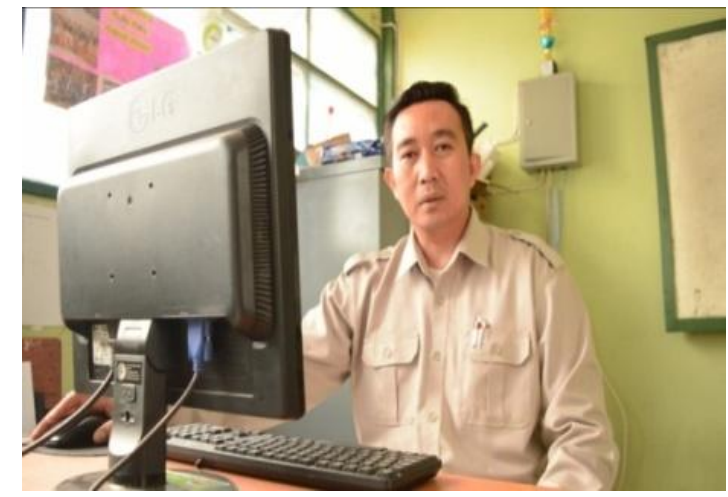

Gambar 18: Video Wawancara humas SMK Yuppentek 4 Ciledug Tangerang

\section{Medium shoot (MS) / EXT \\ Menggambarkan Wawancara Humas SMK Yuppentek 4}

\section{Scene 18}

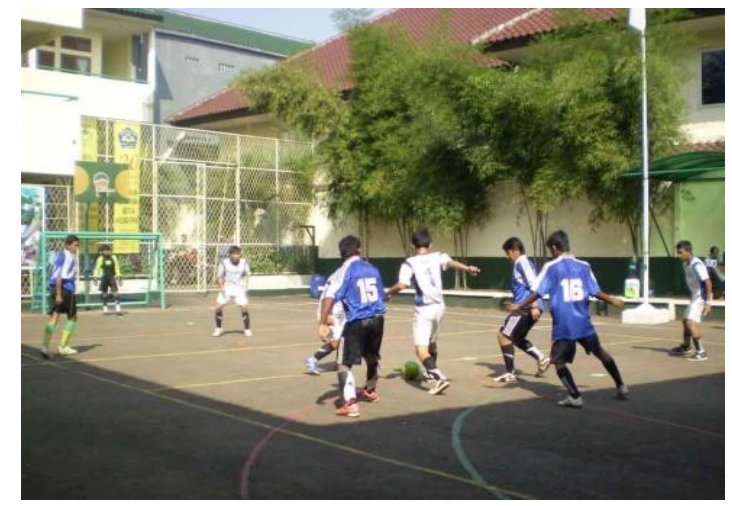

Gambar 19: Video Futsal SMK

Yuppentek 4 Ciledug Tangerang

Medium shoot (MS) / EXT

Menggambarkan Futsal SMK Yuppentek 4 


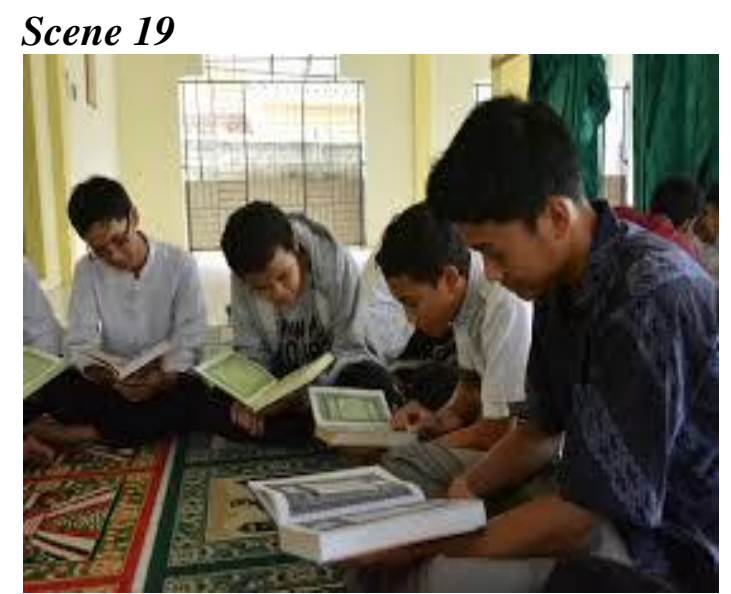

Gambar 20: Video Rohani Islam

Medium Shoot (MS)/ INT Menggambarkan Rohani Islam SMK Yuppentek 4

\section{Scene 20}

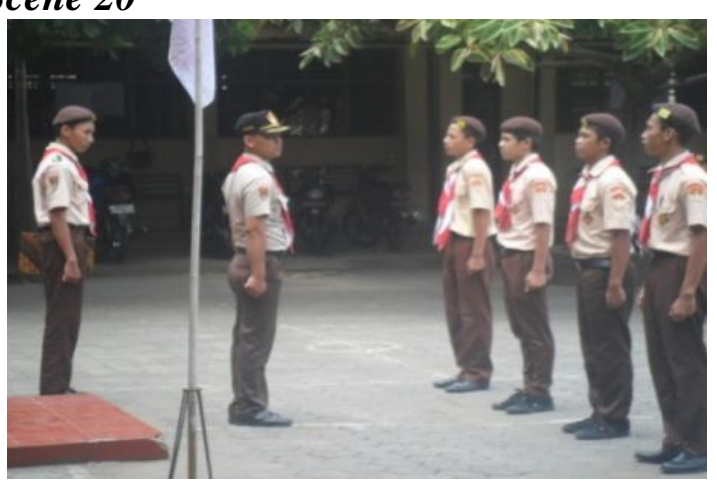

Gambar 21: Video Pramuka

Full Shoot (FS) / EXT

Menggambarkan Pramuka SMK Yuppentek 4

\section{Scene 21}

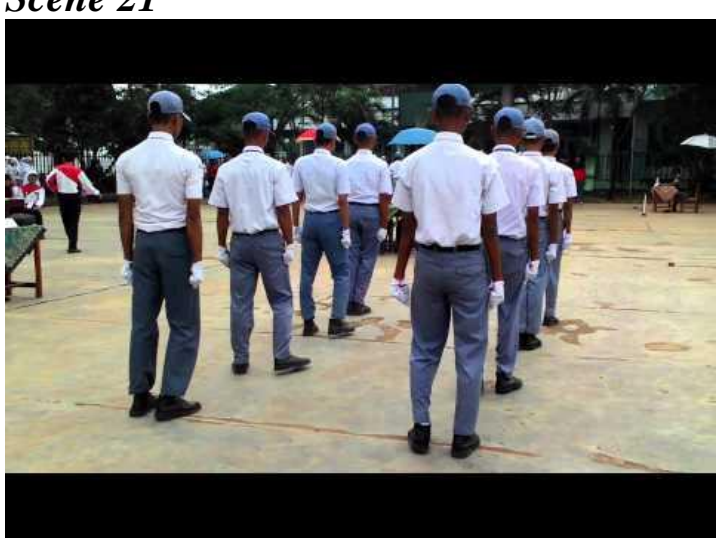

Gambar 22: Video Paskibra

Full Shoot (FS) / EXT

Menggambarkan Paskibra SMK Yuppentek 4

\section{Scene 22}

MARI SEGERA BERGABUNG BERSAMA KAMI DI SMK YUPPENTEK 4 CILEDUG KOTA TANGERANG

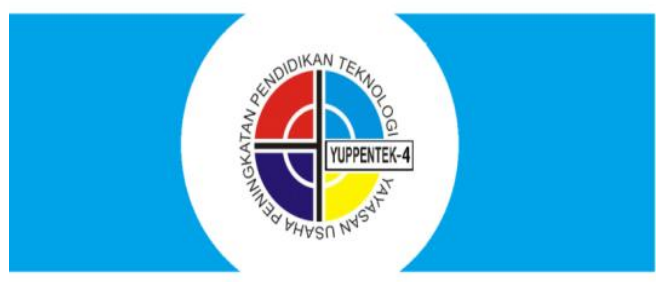

JI.Raden fatah km.1 Ciledug Kota tangerang Telp : (021) 7307941 Email : att.yupp@gmail.com

Gambar 23: Video Variasi title, logo dan alamat sekolah

\begin{tabular}{|c|}
\hline $\begin{array}{c}\text { Menggambarkan Logo dan } \\
\text { alamat sekolah SMK } \\
\text { Yuppentek } 4\end{array}$ \\
\hline
\end{tabular}

Scene 23

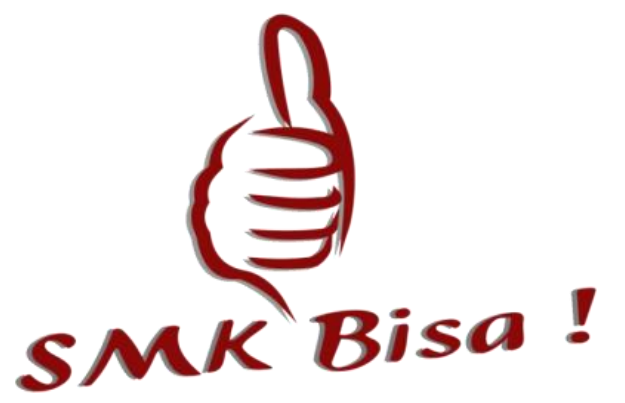

Siap Kerja, Cerdas dan Kompetitif

Gambar 24: Video Logo SMK bisa

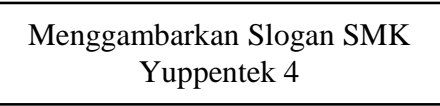

\section{Production}

Production adalah proses pengambilan gambar atau shootingvideo dengan bekerjasamanya antara pemain dan crew untuk pewujudan rumusan dari tahap preproduction dalam bentuk skenario, naskah, dan storyboard yang telah dibuat. Pada tahap production semua unsur teknis dan kreatif seperti naskah, actor, sinematografi dan suara bergabung dibawah pengawasan kreatif sutradara. Dalam menjalankan proses production pengambilan gambar atau shootingvideo ada beberapa hal yang harus dipersiapkan dengan baik, diataranya : desain produksi termasuk storyboard yang bisa menjadi panduan yang baik tentang hal-hal yang harus dikerjakan selama shooting, 
kesiapan crew dalam menjalankan perannya masing-masing dan kesiapan perlengkapan yang juga merupakan tanggung jawab masing-masing crew.

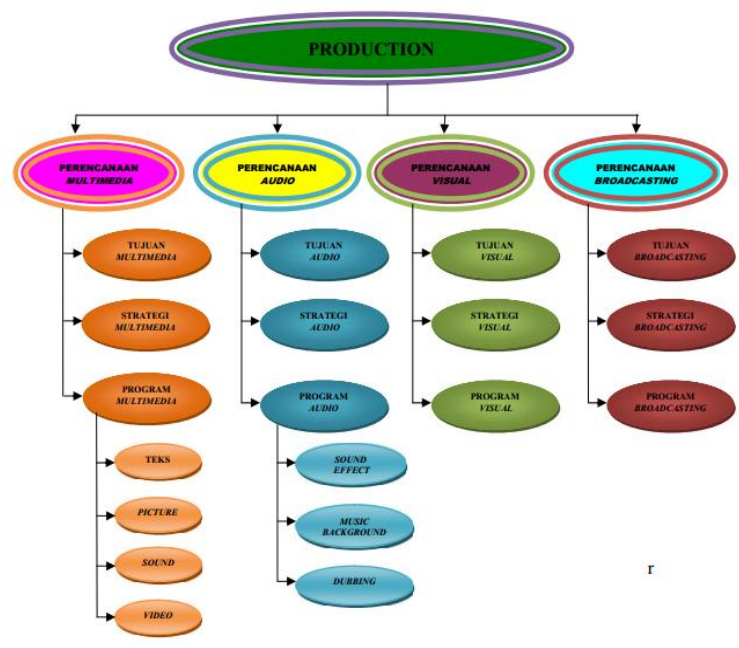

\section{Gambar 25. Production}

\section{Strategi Multimedia}

Geografi Wilayah Kabupaten dan
Kota Tangerang

Demografi : • Jenis Kelamin : Pria \& Wanita

- Kelas Ekonomi : Menengah Menengah Bawah

- Usi : 13 - 16 tahun

- Sasaran : 1. Siswa-siswi SMP / Setara

\section{Program Multimedia}

\section{Program Audio}

Setiap audio yang diterapkan untuk mengisi suara diambil dari video yang sudah dipersiapkan sesuai dengan kebutuhan dari media informasi yang dirancang, diambil dari musik mp3, dicari sound efek yang sesuai. Adanya program editing memudahkan untuk membuat audio kemudian dilakukan proses penyesuaian rancangan video yang akan disuguhkan kepada masyarakat.

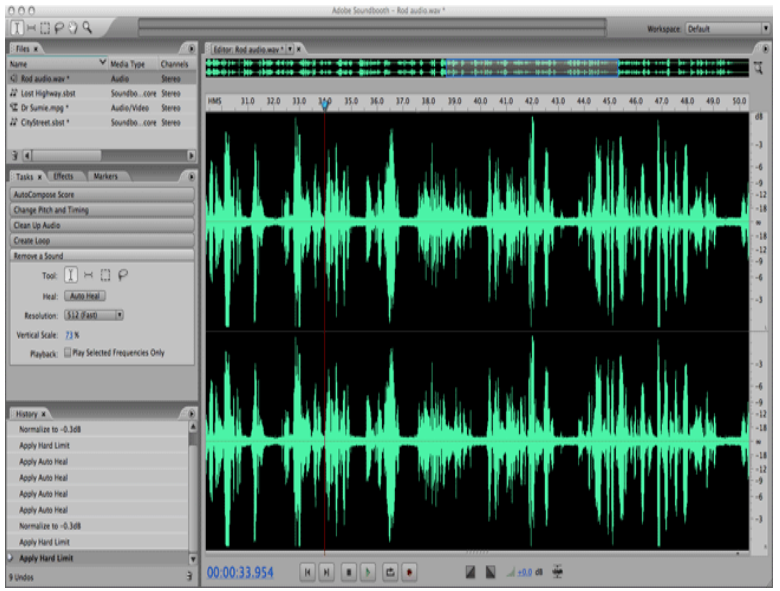

Gambar 25. Adobe Soundbooth

\section{Adobe Premier Pro 5.0}

Didalam proses produksi inilah perancangan spesial effects dibuat menggunakan aplikasi-aplikasi yang merupakan hasil dari kemajuan teknologi. Acuan storyboard diubah menjadi animatrix yaitu semacam slideshow dari storyboard yang sudah diisi dengan dialog yang belum diedit.

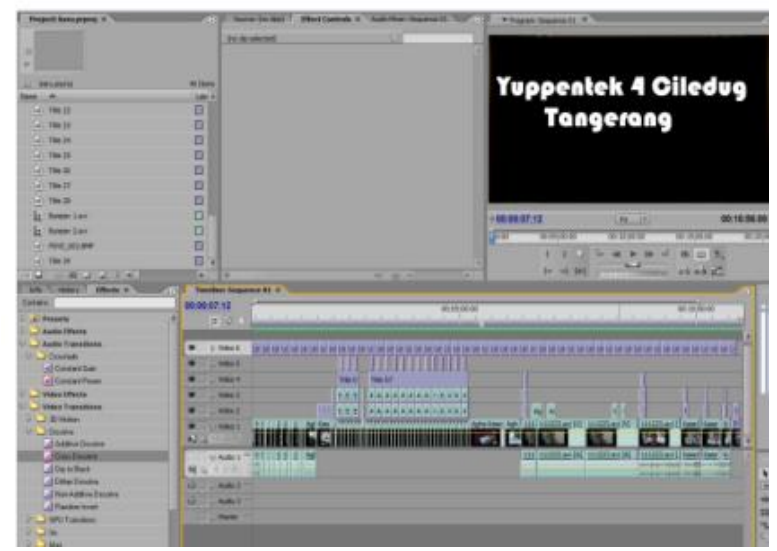

Gambar 26. Adobe Premiere Pro

\section{Anggaran Produksi}

\begin{tabular}{|l|l|l|}
\hline No. & Alat Produksi & Keterangan \\
\hline 1. & $\begin{array}{l}\text { Kamera } \\
\text { Panasonic HDC } \\
\text { MDH1 Full HD }\end{array}$ & $\begin{array}{l}\text { Rp 250.000 } \\
\text { per hari } \\
\text { @ 4 hari = Rp } \\
1.000 .000\end{array}$ \\
\hline 2. & Nikon D3200 & Milik sendiri \\
\hline 3. & Tripod & $\begin{array}{l}\text { Rp 25.000 per } \\
\text { hari }\end{array}$ \\
\hline
\end{tabular}




\begin{tabular}{|c|c|c|}
\hline & & $\begin{array}{l}@ 4 \text { hari }=\mathrm{Rp} \\
100.000\end{array}$ \\
\hline 4. & Slider & $\begin{array}{l}\text { Rp } 50.000 \text { per } \\
\text { hari } \\
@ 4 \text { hari }=\text { Rp } \\
200.000\end{array}$ \\
\hline 5. & Mic condenser & $\begin{array}{l}\text { Rp } 50.000 \text { per } \\
\text { hari } \\
@ 4 \text { hari }=\text { Rp } \\
200.000\end{array}$ \\
\hline 6. & Kru produksi & $\begin{array}{l}\text { Rp } 100.000 \\
\text { per hari } \\
@ 4 \text { hari = Rp } \\
400.000\end{array}$ \\
\hline 7. & Aktor & $\begin{array}{l}\text { @ } 4 \text { hari }=\text { Rp } \\
200.000\end{array}$ \\
\hline \multicolumn{2}{|r|}{ TOTAL } & $\operatorname{Rp} 2.100 .000$ \\
\hline
\end{tabular}

Table 1.Anggaran Produksi

\section{Postproduction}

Tahap postproduction adalah proses finishing sebuah karya sampai menjadi sebuah video yang utuh dan mampu menyampaikan sebuah cerita atau pesan kepada audience. Dalam proses postproduction semua gambar yang didapat pada proses production di satukan dan di edit oleh seorang editor. Kegitan pemutaran dan distribusi juga masuk di dalam proses postproduction. Tahapan proses postproduction, yaitu :

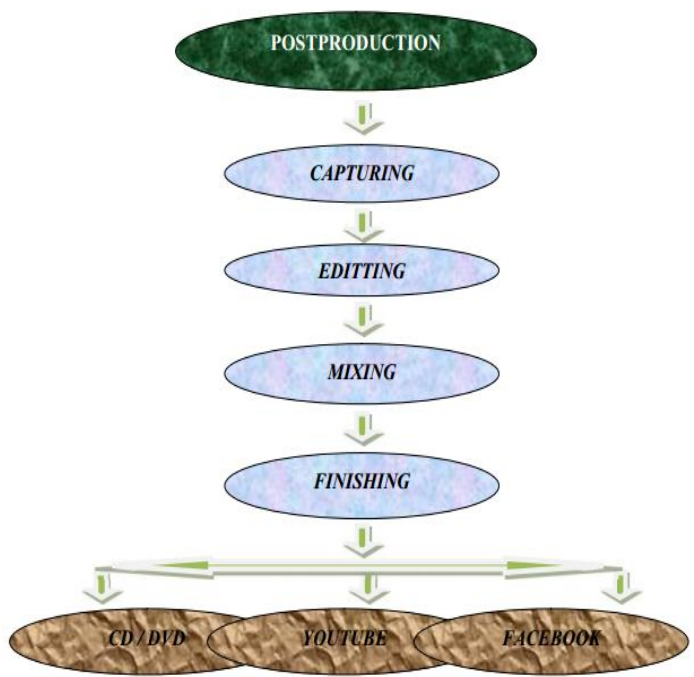

Gambar 27. Postproduksi

\section{KESIMPULAN}

Media Audio Visual sebagai media promosi dan informasi yang dikemas dalam bentuk video sangat di perlukan bagi SMK Yuppentek 4 Ciledug Tangerang yang bertujuan meningkatkan suatu image atau citra dan memberikan informasi kepada masyarakat khususnya orang tua yang akan menyekolahkan putra dan putrinya di SMK Yuppentek 4 Ciledug Tangerang. Pembuatan sebuah media video profile harus memperhatikan faktor-faktor yang berhubungan dengan sekolah yang bersangkutan dalam hal ini penulis menyusuaikan dengan keinginan stakeholder, mulai dari pembuatan video dan audio, tampilan, isi pesan dan penutup. Hal ini bertujuan untuk memperkuat SMK Yuppentek 4 Ciledug Tangerang dalam mempromosikan dan menginformasikan profile sekolah. Pembuatan sebuah media audio visual yang menarik dan dapat memenuhi kebutuhan masyarakat yaitu dengan membuat sebuah video yang berisikan infomasi-informasi profile sekolah tersebut, yang berisikan dari beberapa video yang berisi teks, gambar, dan background suara dan disertakan beberapa spesial efek sehingga tampak lebih menarik.

\section{DAFTAR PUSTAKA}

[1] Arifin, Eva. 2010. Broadcasting To Be Broadcaster, Yogyakarta : Graha Ilmu.

[2] Binanto, Iwan. 2010. "Multimedia Digital Dasar (Teori dan Pengembangannya)", Yogyakarta: Andi

[3] Hendratman, Hendi. 2012. "The Magic of Adobe After Effects", Informatika, Bandung.

[4] Liliweri. 2011.Teknik Membuat Iklan.Jakarta : Indie 
[5] Pujiriyanto. 2012. Pengajaran Pemahaman melalui Desain. Jakarta : Indeks

[6] Rahardja, Untung. Sugeng Widada. Dewi Immaniar Desrianti . 2010. KPM Sebagai Pedoman Produksi Media MAVIB (Multimedia Audio Visual and Broadcasting) Journal CCIT Vol.3 No.2.

[7] Rahmawati, Indah. 2011. "Menjadi Sutradara Televisi : dengan Single dan Multi Camera". Jakarta: Grasindo.

[8] Yakub. 2012. Pengantar Sistem Informasi. Yogyakarta : Graha Ilmu. 